\title{
Genetic Variation in Bovine Mononuclear Leukocyte Responses to Dexamethasone
}

\author{
P. M. Saama, ${ }^{1}$ J. B. Jacob, ${ }^{1}$ M. E. Kehrli, Jr., ${ }^{2}$ A. E. Freeman, ${ }^{3}$ S. C. Kelm, ${ }^{3}$ \\ A. L. Kuck, ${ }^{4}$ R. J. Tempelman, ${ }^{1}$ and J. L. Burton ${ }^{1}$ \\ ${ }^{1}$ Department of Animal Science, Michigan State University, East Lansing 48824 \\ ${ }^{2}$ USDA-ARS, National Animal Disease Center, Ames 50010 \\ ${ }^{3}$ Department of Animal Science, lowa State University, Ames 50011 \\ ${ }^{4} 21$ st Century Genetics CRI, Shawano, WI 54166-9988
}

\begin{abstract}
The objective of this study was to determine whether bovine mononuclear leukocytes exhibit genetic variability prior to and after a glucocorticoid hormone challenge in vivo. Test animals included 60 pedigreed Holstein bulls treated on 3 consecutive days with dexamethasone and 5 untreated control bulls. Eight indicator traits of leukocyte responsiveness to dexamethasone included the percentages of circulating B cells, T cells (CD4, CD8, and workshop cluster 1 molecule expressed by bovine $\gamma \delta$ T cell), major histocompatibility complex (MHC) I and II expressing cells, and mean expressions of surface MHC I and MHC II on circulating cells. Blood for this work was collected from each test bull 10 times before, during, and after dexamethasone administration, with corresponding samples taken for control bulls. Random regression models with treatment-specific serial correlation were applied to the leukocyte data sets to estimate genetic and nongenetic sources of variation in baseline and recovery aspects of the traits. All traits responded predictably to glucocorticoid challenge. Genetic variation was observed in baseline measurements of all traits, with heritability estimates ranging from $0.21 \pm 0.03$ to $0.60 \pm 0.06$. Genetic variation in linear recovery from nadir values following dexamethasone administration was significant only for percentage CD4, percentage CD8, and for surface expression of MHC II. The genetic covariance between basal and linear recovery was positive and significant for percentage CD4, percentage CD8, and MHC II expression. The bovine lymphocyte antigen DRB3.2 locus accounted for significant proportions of total variation in percentage MHC II cells and MHC I expression. These results suggest that genetic variability exists for important basal and glucocorticoid-modified phenotypes of bovine mono-
\end{abstract}

\footnotetext{
Received February 13, 2004.

Accepted July 24, 2004.

Corresponding author: J. L. Burton; e-mail: burtonj@pilot. msu.edu.
}

nuclear leukocytes, implying that immunocompetence traits impacted by this stress hormone may be enhanced by genetic selection.

(Key words: dairy cattle, leukocyte, dexamethasone, heritability)

Abbreviation key: APC = antigen presenting cell, BoLA = bovine lymphocyte antigen, $\mathbf{M H C}=$ major histocompatibility complex, $\mathbf{P E}=$ phycoerythrin, $\mathbf{W C 1}=$ workshop cluster 1 molecule expressed by bovine $\gamma \delta$ $\mathrm{T}$ cell.

\section{INTRODUCTION}

Phenotypes of bovine leukocytes are influenced by the blood environment, including circulating concentrations of steroid hormones (Burton and Erskine, 2003; Eicher and Burton, 2004). In particular, the stress steroids (glucocorticoids) have well-documented effects on trafficking patterns of blood B cells, $\gamma \delta \mathrm{T}$ cells, and neutrophils (Oldham and Howard, 1992; Burton and Kehrli, 1996; Anderson et al., 1999) and profoundly affect the expression of neutrophil CD62L and CD18 adhesion molecules (Cronstein et al., 1992; Burton et al., 1995; Weber et al., 2001, 2004). Glucocorticoids also affect mononuclear leukocyte expression of major histocompatibility complex (MHC) class I and II molecules (Burton and Kehrli, 1996), the ability of mononuclear leukocytes to produce and express proinflammatory cytokines, cytokine receptors, and antibodies (Nonneche et al., 1997; Yu et al., 1997; Anderson et al., 1999), and the performance of neutrophils and mononuclear leukocytes in response to chemoattractants, mitogens, and antigens in vitro (Roth and Kaeberle, 1982; Roth et al., 1984; Oldham and Howard, 1992). These changes in leukocyte functions have been associated with both heightened expression of infectious diseases and reduced local inflammation in glucocorticoid-treated cattle (Lohuis et al., 1988; Wesley et al., 1989; Chiang et al., 1990; Burton and Kehrli, 1995).

Similar to glucocorticoid-treated cattle, parturient cows also exhibit depressed local inflammatory re- 
sponses and heightened risk for opportunistic infectious diseases, especially mastitis (Kehrli and Harp, 2001; Burton and Erskine, 2003). There is good indication that parturition-induced alterations in the phenotypes of bovine leukocytes is under genetic control, as heritabilities of many in vitro functional traits of these white blood cells range from moderate to high (Detilleux et al., 1994; Kelm et al., 1997). Glucocorticoids are an important part of the parturient blood environment (Preisler et al., 2000; Weber et al., 2001), and leukocytes from male and female dairy cattle express cytoplasmic receptors for this family of steroids and respond to the hormones with similar gene expression and phenotypic changes in vivo and in vitro (Weber et al., 2001; Madsen et al., 2004; Weber et al., 2004). In the current study, we hypothesized that responsiveness of bovine mononuclear leukocytes to glucocorticoid challenge in vivo would exhibit genetic variation, as we recently showed was the case for bovine neutrophils (Tempelman et al., 2002). In that study, longitudinal heritability estimates ranged from 0.10 to 0.54 for neutrophil expression of the CD18 adhesion molecule and from 0.11 to 0.24 for an associated trait, blood neutrophil count.

In the current study, we wanted to know whether additional glucocorticoid-sensitive traits related to proportions of various circulating mononuclear leukocytes and their surface expression of MHC class I and II antigens exhibit genetic variability in dairy cattle. Given the availability of accurate pedigree information for dairy sires vs. dams and the relative ease in performing controlled longitudinal studies in a bull stud vs. on dairy farms, we elected to test our hypothesis using a group of 60 registered AI bulls (the test bulls). Leukocytes from a small group of control bulls were also sampled so we could monitor daily variation in the laboratory assays performed. We recorded information for 8 mononuclear leukocyte traits shown in our previous studies to respond to glucocorticoid challenge (Burton and Kehrli, 1996; Nonnecke et al., 1997) and applied random regression models with treatment (glucocorticoid)-specific serial correlation to infer upon genetic variation in the longitudinal data sets collected (Tempelman et al., 2002).

\section{MATERIALS AND METHODS}

\section{Test Population}

Sixty-five young (mean BW \pm SD $=406.57 \pm 70.07$ ) registered Holstein AI bulls (21st Century Genetics CRI, Shawano, WI) were used in this study. Sixty of these bulls were selected to receive glucocorticoid treatments (test bulls; see subsequently). The remaining 5 bulls were not treated with glucocorticoid; leukocytes from these animals were used simply to monitor daily variation in the phenotyping assays performed. To ensure genetic diversity in the 60 test bulls, animals were genotyped at the bovine lymphocyte antigen (BoLA) DRB3.2 locus (i.e., MHC II locus) by PCR-RFLP method described in Dietz et al. (1997). Pedigree information available on these bulls included sire and maternal grandsire identifications.

\section{Glucocorticoid Challenge and Blood Collections}

The synthetic glucocorticoid dexamethasone (Azium; Schering Corp., Kenilworth, NJ) was injected intramuscularly into the 60 test bulls at a dose of $0.04 \mathrm{mg} / \mathrm{kg}$ of BW every $24 \mathrm{~h}$ for 3 consecutive d (on study d 0,1 , and 2). This dose of dexamethasone was previously shown to impact numbers of circulating $\mathrm{T}$ and $\mathrm{B}$ lymphocytes, expression of surface MHC molecules, and production of interferon- $\gamma$ and antibodies by mitogen- and antigenstimulated mononuclear leukocytes (Burton and Kehrli, 1996; Nonnecke et al., 1997). Blood (250 mL/bull per sample time) was collected 10 times per bull by jugular puncture into acid citrate dextrose, on $\mathrm{d}-5,-4$, $-3,2,3,4,5,9,10$, and 11 relative to the first hormone injection (on d 0 ) and was shipped via overnight express mail to the USDA laboratory in Iowa for processing and leukocyte phenotyping (within $24 \mathrm{~h}$ of collection).

Because of practical considerations related to blood sampling, shipping, and laboratory processing, groups of 12 test bulls were brought into the trial at any one time. Thus, there were 5 study rounds with 12 test bulls per round. Two control bulls were available for use in all 5 rounds. However, we sought to have a total of 4 control bulls per round. Thus, 2 additional control bulls were added at each round according to their availability at the AI stud. In total, 5 individual control bulls were used in this 18-mo study. Blood was sampled from the 4 control bulls of each round every time the 12 test bulls were sampled, for leukocyte phenotyping. Leukocyte phenotype data from d 5 of one round were not collected because corresponding blood samples did not arrive at the laboratory within $24 \mathrm{~h}$ of collection at the bull stud. Data from these samples were treated as missing observations in the statistical analyses.

\section{Mononuclear Leukocyte Phenotyping}

Mononuclear leukocytes for phenotyping were enriched from whole blood using Percoll density gradient centrifugation according to the methods of Kehrli et al. (1989). Cells were washed twice in PBS and seeded at $5 \times 10^{5}$ cells/well (100 $\mu \mathrm{L}$ total volume) into 96 -well, round bottom microtiter plates for subsequent immunostaining to monitor percentages of CD4 T cells, CD8 T cells, workshop cluster 1 molecule expressed by bovine 
Table 1. Primary antibodies used to monitor percentage CD4 T cells, percentage CD8 T cells, percentage WC $1^{1+} \gamma \delta$ T cells, percentage B cells, percentage $\mathrm{MHC}^{2}$ I cells, percentage MHC II cells, and expression of MHC I and MHC II in mononuclear leukocytes purified from blood of test and control bulls.

\begin{tabular}{|c|c|c|c|}
\hline \multirow[b]{2}{*}{ Specificity (cell type) } & \multicolumn{3}{|c|}{ Primary antibodies (monoclonals) } \\
\hline & Clone (isotype) & $\begin{array}{l}\text { Working solution } \\
\text { (in } 0.01 \% \text { BSA-PBS) }\end{array}$ & Source \\
\hline CD4 $\left(\mathrm{T}_{\mathrm{H}}\right.$ cells $)$ & IL-A11 $\left(\operatorname{IgG}_{1}\right)$ & $1 / 50$ & ILRAD $^{3}$ \\
\hline $\mathrm{CD} 8\left(\mathrm{~T}_{\mathrm{C}}\right.$ cells $)$ & CACT80C $\left(\mathrm{IgG}_{1}\right)$ & $7 \mu \mathrm{l} / \mathrm{mL}$ & $\mathrm{VMRD}^{4}$ \\
\hline $\mathrm{WC} 1(\gamma \delta \mathrm{T}$ cells $)$ & IL-A29 $\left(\operatorname{IgG}_{1}\right)$ & $1 / 400$ & ILRAD \\
\hline $\operatorname{IgM}_{\text {surface }}(\mathrm{B}$ cells $)$ & $\mathrm{BAQ} 155 \mathrm{~A}\left(\mathrm{IgG}_{1}\right)$ & $3.5 \mu \mathrm{l} / \mathrm{mL}$ & VMRD \\
\hline MHC I (all cells) & $\mathrm{H} 58 \mathrm{~A}\left(\mathrm{IgG}_{2 \mathrm{a}}\right)$ & $7 \mu \mathrm{l} / \mathrm{mL}$ & VMRD \\
\hline $\mathrm{MHC}$ II $\left(\mathrm{APC}^{5}\right)$ & $\mathrm{H} 42 \mathrm{~A}\left(\mathrm{IgG}_{2 \mathrm{a}}\right)$ & $7 \mu \mathrm{l} / \mathrm{mL}$ & VMRD \\
\hline
\end{tabular}

${ }^{1} \mathrm{WC} 1$ = Workshop cluster 1 molecule.

${ }^{2} \mathrm{MHC}=$ Major histocompatibility complex .

${ }^{3}$ ILRAD = Institute for Livestock Research in Animal Diseases, Nairobi, Kenya

${ }^{4}$ Concentration of VMRD (Pullman, WA) monoclonal antibodies was $1 \mu \mathrm{g} / \mathrm{mL}$.

${ }^{5} \mathrm{APC}=$ Antigen presenting cell.

$\gamma \delta \mathrm{T}$ cells (WC1), B cells, and MHC I- and MHC IIbearing antigen presenting cells (APC). Mean expression of MHC I and MHC II on APC was also determined as mean fluorescence intensity (Burton and Kehrli, 1995, 1996).

Leukocyte immunostaining was done using a 2-antibody system, exactly as described in Burton and Kehrli (1996). The primary monoclonal antibodies used to label specific cells are listed in Table 1 . The secondary (detection) antibody was phycoerythrin (PE)-conjugated goat antimouse $\operatorname{IgG}_{(\mathrm{H}+\mathrm{L})} \mathrm{F}\left(\mathrm{ab}^{\prime}\right)_{2}$ (Boehringer Mannheim, Indianapolis, IN) diluted 1:100 in PBS containing 0.01\% bovine serum albumin (Sigma Chemical Co., St. Louis, $\mathrm{MO})$. Irrelevant isotype-matched $\mathrm{PE}$-conjugated anti-

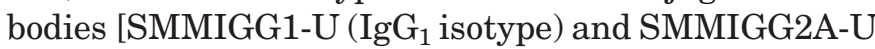
( $\mathrm{IgG}_{2 \mathrm{a}}$ isotype); R\&D Systems, Minneapolis, MN] were used undiluted as negative controls to account for nonspecific (background) fluorescence of cells. Data acquisition was done using a FACScan flow cytometer and CellQuest software (Becton Dickinson, San Jose, CA). Immunostained mononuclear cells were first viewed in forward-side scatter density dot plots to determine purity (always $>98 \%$ ) based on characteristic size and granularity parameters of the cells (Burton and Kehrli, 1996). The PE fluorescence of the various immunostained cell samples was then determined from FL-2 (PE) fluorescence histogram plots. Data from 5000 events (cells) were acquired for each sample. Regions of background fluorescence were identified and marked based on histogram plots for the irrelevant isotype controls ( $>98 \%$ of all events counted from these samples), and events to the right of this marker were considered the cells that stained positive for the marker (phenotype) of interest. Once established, the marker separating background and positive fluorescence was not altered for the duration of the study, so detection of even subtle effects of dexamethasone on the mononuclear leukocyte traits was possible.

\section{Statistical Model and Analysis}

The statistical methods used in this study were similar to those we used previously to study genetic variation in blood neutrophil traits (Tempelman et al., 2002). All data sets were checked for normality of distributions prior to statistical analyses. Accordingly, percentage data were square root- and inverse sine-transformed, and mean fluorescence intensity data were logarithmically transformed to stabilize variances and minimize skewness.

The statistical model used to analyze the transformed data sets was almost identical to that shown in Tempelman et al. (2002), except that it also included the random effect of BoLA (DRB3.2) locus:

$$
\begin{gathered}
y_{i j k l m}=\mu+\text { trt }_{i}+\text { day }_{j}+\text { round }_{k}+(\text { trt } \cdot \text { day })_{i j} \\
+(\text { trt } \cdot \text { round })_{i k}+\left(\text { round } \cdot d a y_{j k}\right. \\
+(\text { trt } \cdot \text { round } \cdot \text { day })_{i j k}+\beta\left(x_{l}-\overline{\mathbf{x}}\right)+u_{l} \\
+b_{l}\left(11-\text { day }_{j}\right)_{i=2}^{+}+\text {bola }_{m_{1}}+\text { bola }_{m_{2}}+p_{i j k l}+e_{i j k l m}
\end{gathered}
$$

where $y_{i j k l m}$ is the response for traits of the $l$ th bull having BoLA genotype $m=\left[m_{1} m_{2}\right]$ within the $i$ th treatment group on the $j$ th day within the $k$ th round; $\mu$ is the overall mean; $\operatorname{trt}_{i}$ is the fixed effect of the $i$ th treatment group ( $i=1$ for control; $i=2$ for test); $d a y_{j}$ is the fixed classification effect of the $j$ th study day $(j=1,2, \ldots, 10)$; round $_{k}$ is the fixed effect of the $k$ th study round $(k=1$, $2, \ldots, 5) ;(t r t d a y)_{i j}$ is the interaction between the $i$ th treatment group and the $j$ th day; (trt round) ${ }_{i k}$ is the interaction between the $i$ th treatment and the $k$ th round; (day round $)_{j k}$ is the interaction between the $j$ th 
day and the $k$ th round; (trt day round) $)_{i j k}$ is the 3-way interaction between the $i$ th treatment, the $j$ th day, and the $k$ th round; $\beta$ is the regression coefficient on bull weight $x_{l}$ expressed as deviation from the mean bull weight $\bar{x} ; u_{l}$ is the random genetic baseline effect of the $l$ th bull; $b_{l}$ is the random genetic deviation for linear recovery to basal levels in test bulls postdexamethasone administration; bola $m_{m_{1}}$ and bola $m_{m_{2}}$ are the random effects of the 2 alleles/haplotypes $m_{1}$ and $m_{2}$ at the BoLA locus; $p_{i j k l}$ is the random common environmental effect for the $l$ th bull in the $i$ th treatment group on the $j$ th day within the $k$ th round; and $e_{i j k l}$ is the temporary environmental effect (and/or measurement error) pertaining to the observation on the $l$ th bull in the $i$ th treatment group on the $j$ th day within the $k$ th round. Here, $(11-\text { day })_{i=2}^{+}$is simply a reparameterized day covariate for test bulls after dexamethasone administration. More specifically, $\left(11-d a y_{j}\right)_{i=2}^{+}=\left(11-d a y_{j}\right)$ if $d a y_{j}$ $>0$, and $\left(11-d a y_{j}\right)_{i=2}^{+}=0$ if $d a y_{j} \leq 0$ such that $(11-$ $\left.d a y_{j}\right)_{i=2}^{+}=0,0,0,9,8,7,6,2,1$, and 0 for $d a y_{j}=-5$, $-4,-3,2,3,4,5,9,10$, and 11 , respectively, for test bulls $(i=2)$. In contrast, $\left(11-d a y_{j}\right)_{i=1}^{+}=0$ for all days $j=1,2, \ldots, 10$, for control bulls $(i=1)$ (i.e., genetic variation in linear recovery to basal levels can only be modeled for test bulls). This particular covariate reparameterization was used because of its numerical stability for variance component estimation. Because dexamethasone was anticipated to change phenotypes in both up and down directions (Burton and Kehrli, 1996), $b_{l}$ was used to model the genetic merit of the $l$ th bull in its linear rate of recovery to baseline values from first dexamethasone administration (d 0) up until d 11. It should be noted that the genetic variability in trait changes from pre to postdexamethasone time points is of potential interest, but that practical issues related to sample collections at the bull stud precluded our ability to collect enough sampling points to adequately characterize this variability. It should also be noted that we attempted to model genetic variation in the quadratic rate to postdexamethasone recovery (as in Tempelman et al., 2002) but that REML nonconvergence problems and convergence to zero estimates invariably occurred.

Allelic effects at the BoLA locus were modeled as normally, independently, and identically distributed random additive effects with haplotypic variance component $\sigma_{\text {bola }}^{2}$ common to both alleles within each bull such that the combined variance due to the BoLA locus was $2 \sigma_{\text {bola }}^{2}$. Treating allelic effects as random is advisable (Van Arendonk et al., 1999), particularly when there are many alleles, some with relatively low frequencies, as occurred in our data set (see Table 2).
Table 2. Frequencies of alleles at the DRB3.2 (i.e., major histocompatibility complex II) locus for the 60 test bulls and 5 control bulls used in the current study.

\begin{tabular}{lc}
\hline Allele & Frequency \\
\hline 2 & 2 \\
3 & 6 \\
7 & 12 \\
8 & 16 \\
10 & 2 \\
11 & 1 \\
12 & 1 \\
16 & 15 \\
18 & 4 \\
22 & 19 \\
23 & 27 \\
24 & 12 \\
27 & 5 \\
\hline
\end{tabular}

The distributional assumptions about the genetic effects were as follows:

$$
\left[\begin{array}{l}
\mathbf{u} \\
\mathbf{b}
\end{array}\right] \sim N\left(\left[\begin{array}{l}
\mathbf{0} \\
\mathbf{0}
\end{array}\right], \mathbf{G} \otimes \mathbf{A}=\left[\begin{array}{c}
\mathbf{A} \sigma_{u}^{2} \mathbf{A} \sigma_{u b} \\
\mathbf{A} \sigma_{u b} \mathbf{A} \sigma_{b}^{2}
\end{array}\right]\right)
$$

where $\mathbf{u}=\left[u_{1}, u_{2}, \ldots, u_{65}\right]^{\prime}$ is the vector of random genetic baseline effects, $\mathbf{b}=\left[b_{1}, b_{2}, \ldots ., b_{65}\right]^{\prime}$ is the vector of postdexamethasone-influenced random genetic deviations in linear rate to recovery, and $\otimes$ denotes the Kronecker or direct product (Searle, 1982). Here, A is the numerator relationship matrix between bulls based on 2 generations of male ancestry information (Henderson, 1976) on each bull; that is its sire, maternal grandsire, and paternal grandsire. The genetic variance-covariance matrix $\mathbf{G}$ includes the basal genetic variance $\sigma_{u}^{2}$, the genetic variance in linear rate of recovery postdexamethasone $\sigma_{b}^{2}$, and the genetic covariance $\sigma_{u b}$ between the 2 genetic effects, i.e.

$$
\mathbf{G}=\left[\begin{array}{c}
\sigma_{u}^{2} \sigma_{u b} \\
\sigma_{u b} \sigma_{b}^{2}
\end{array}\right]
$$

Common environmental effects were used to model random nongenetic effects peculiar to each bull within round and were modeled separately for control and test bulls. The common environmental variance $\sigma_{p_{o}}^{2}$ was specified as being homogeneous across all days within the control group. Conversely, common environmental variances $\sigma_{p_{j}}^{2}, j=1,2, \ldots, 10$, were specified as being heterogeneous across days within test bulls with the exception that the common environmental variances were constrained to be of the same value for the $3 \mathrm{~d}(\mathrm{~d}$ $-5,-4$, and -3 ) prior to dexamethasone administration; 
i.e., $\sigma_{p_{1}}^{2}=\sigma_{p_{2}}^{2}=\sigma_{p_{3}}^{2}$, as there was no plausible reason to estimate separate variances for each day prior to dexamethasone administration. Two different common environmental correlation structures across days were investigated separately for control and for test bulls. First, a power correlation structure was specified for test bulls with the common environmental correlation between any $2 \mathrm{~d}$ being modeled as power of the number of days between them, i.e., corr $\left(p_{i j k l}, p_{i j^{\prime} k l}\right)=\rho^{(d a y}{ }_{j}-$ $d a y^{\prime}$ ) for any $j \neq j^{\prime}$ where $\rho$ is an autocorrelation parameter. Second, a uniform correlation structure across days was modeled, i.e., $\operatorname{corr}\left(p_{i j k l}, p_{i j^{\prime} k l}\right)=\rho$ for any $j \neq j^{\prime}$.

The residual (i.e., temporary environment or measurement error) terms $e_{i j k l}$ were assumed to be normally and independently distributed for all records; however, variances were modeled separately for each of the following 3 situations: 1) data on all control bulls and on test bulls prior to dexamethasone administration with common residual variance $\sigma_{e_{1}}^{2}$,2) data on test bulls immediately following dexamethasone administration ( $\mathrm{d}$ $2,3,4$, and 5) with common residual variance $\sigma_{e_{2}}^{2}$, and 3 ) data on test bulls well after dexamethasone administration $(\mathrm{d} 9,10$, and 11$)$ with common residual variance $\sigma_{e_{3}}^{2}$.

Variance components were estimated by REML using ASREML (Gilmour et al., 2001). Then, inference on treatment effects was based on treating the estimated variance components as if they were known. The average information REML algorithm (Gilmour et al., 1995) is implemented in ASREML such that asymptotic standard errors were readily computed for each variance component based on the average information matrix.

Likelihood ratio tests were used to assess the significance of sources of genetic variation using the necessary modifications for variance components as demonstrated by Stram and Lee (1994). Day-specific LSM \pm 1 SE were computed for test and control bulls and back-transformed under ASREML to the scale of observation for presentation in Figures 1 to 3.

\section{Heritability Estimation}

Heritability is defined as the proportion of the phenotypic variation that can be attributed to genetic variation. Because of the potential impact of dexamethasone on phenotypic variability and its relative partitioning into genetic and environmental components, heritabilities were modeled as heterogeneous over days within each study round, except for $\mathrm{d}-5,-4$, and -3 (i.e., prior to dexamethasone administration). Given that the control bulls are numbered $l=1,2, \ldots, 5$, we write the genetic merit for the $l$ th test bull on the $j$ th day as $g_{j l}=$ (a)

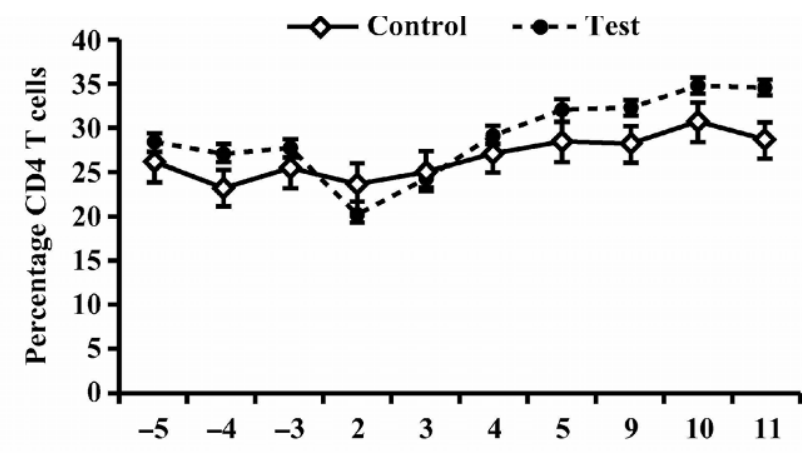

(b)

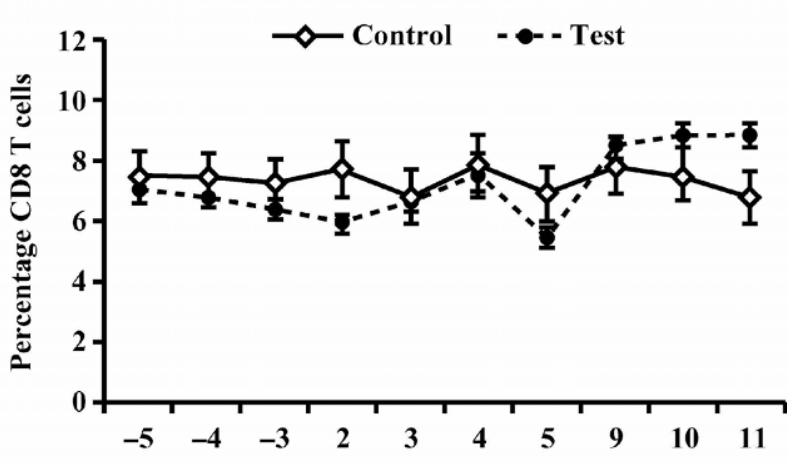

(c)

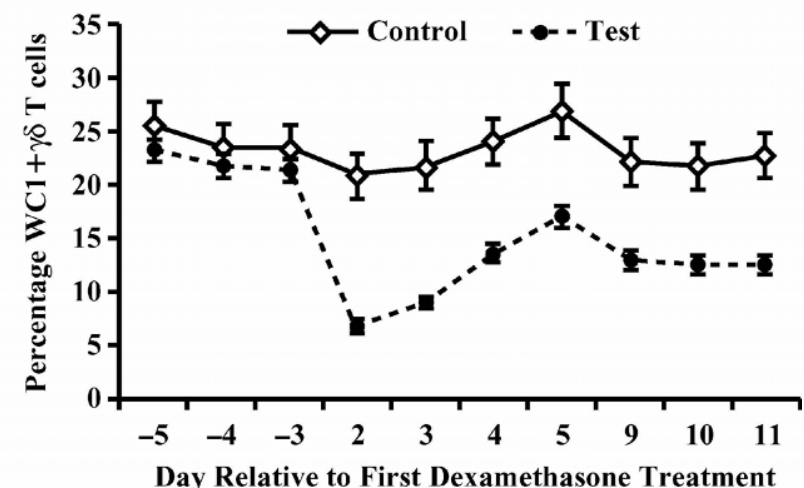

Figure 1. Mean ( \pm SEM) percentage CD4 T cells (a), percentage CD8 T cells (b), and percentage workshop cluster 1 molecule (WC1) $+\gamma \delta \mathrm{T}$ cells (c) in mononuclear fractions of peripheral blood from control bulls ( $\mathrm{n}=5$; solid lines) and dexamethasone-treated test bulls $(\mathrm{n}=60$; dotted lines $)$.

$u_{l}+b_{l}\left(11-d a y_{j}\right)_{i=2}^{+}, l=6,7, \ldots, 65 ; j=1,2, \ldots, 10$. The estimated (non-BoLA) total genetic variance $\hat{\sigma}_{g_{j}}^{2}$ on the $j$ th day can then be readily determined based on the model in [1] as

$$
\begin{gathered}
\hat{\sigma}_{g_{j}}^{2}=\hat{\sigma}_{u}^{2}+2\left(11-d a y_{j}\right)_{i=2}^{+} \hat{\sigma}_{u b} \\
+\left(\left(11-d a y_{j}\right)_{i=2}^{+}\right)^{2} \hat{\sigma}_{b}^{2}, j=1,2,3, \ldots ., 10
\end{gathered}
$$

where $\hat{\sigma}_{u}^{2}, \hat{\sigma}_{u b}$ and $\hat{\sigma}_{b}^{2}$ are REML estimates of the corresponding elements of $\mathbf{G}$ in equation 3. The phenotypic variance $\sigma_{z_{j}}^{2}$ for the $j$ th day can be estimated as: 
(a)

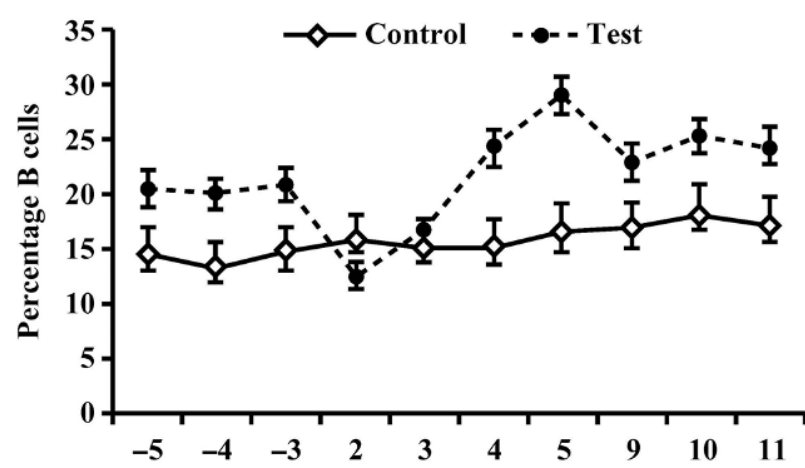

(b)

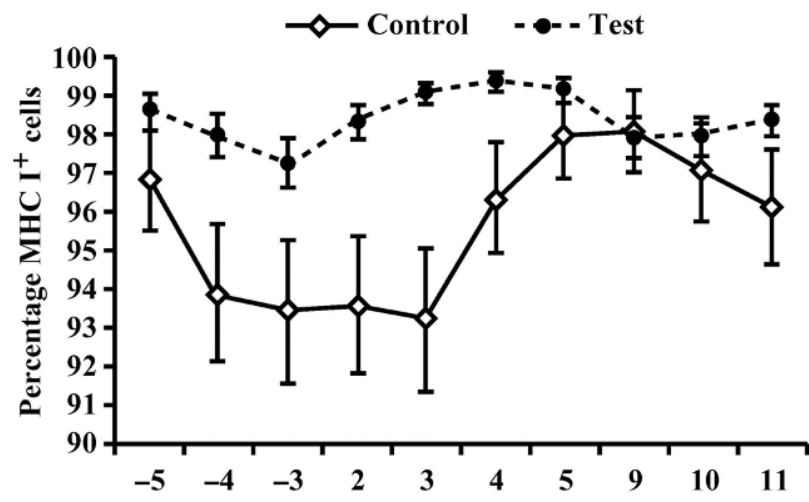

(c)

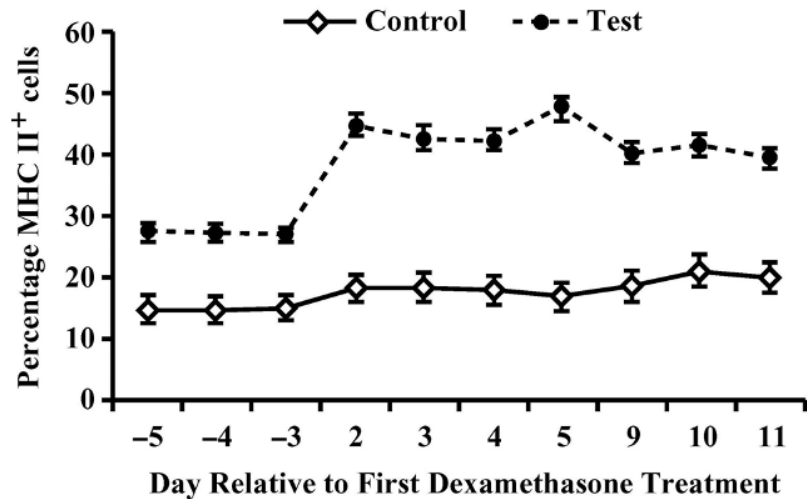

Figure 2. Mean ( \pm SEM) percentage B cells (a), percentage major histocompatibility complex (MHC) I cells (b), and percentage MHC II cells (c) in mononuclear fractions of peripheral blood from control bulls $(\mathrm{n}=5$; solid lines) and dexamethasone-treated test bulls $(\mathrm{n}=$ 60; dotted lines).

$$
\hat{\sigma}_{z_{j}}^{2}=\hat{\sigma}_{g_{j}}^{2}+\hat{\sigma}_{p_{j}}^{2}+2 \hat{\sigma}_{b o l a}^{2}+\hat{\sigma}_{e_{t}}^{2}, j=1,2,3, \ldots ., 10
$$

where $t=1$ for $\mathrm{d}-5,-4$, and $-3 ; t=2$ for $\mathrm{d} 2,3,4$, and 5 ; and $t=3$ for $\mathrm{d} 9,10$, and 11 , allowing for residual (temporary environmental or measurement error) variances that are heterogeneous across the 3 different clusters of days as previously described. Furthermore, $\hat{\sigma}_{\text {bola }}$, $\hat{\sigma}_{p_{j}}^{2}$, and $\hat{\sigma}_{e_{t}}^{2}$ are REML estimates of $\sigma_{\text {bola }}, \sigma_{p j}^{2}, j=1,2,3$, (a)

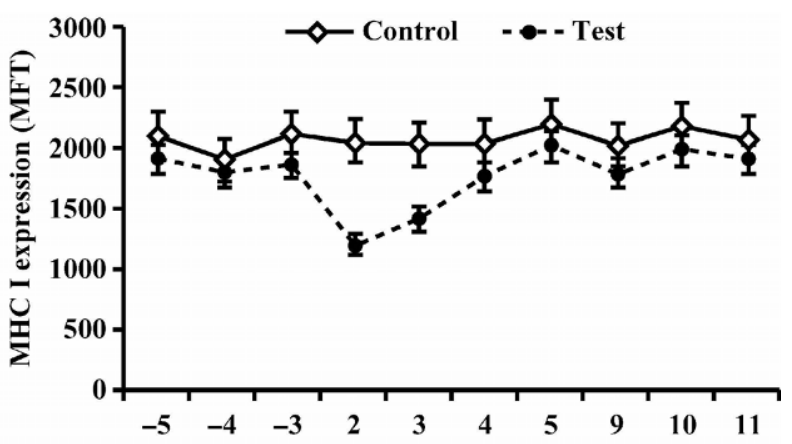

(b)

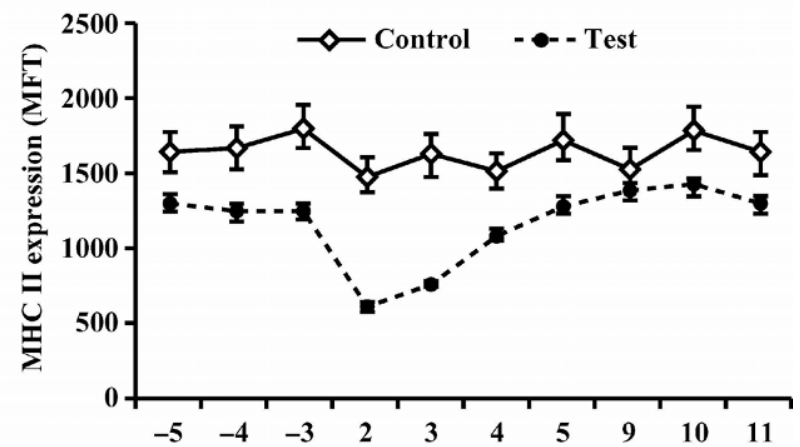

Day Relative to First Dexamethasone Treatment

Figure 3. Mean ( \pm SEM) expression (as mean fluorescence intensity; MFI) of major histocompatibility complex. (MHC) I (a) and II (b) in mononuclear leukocyte fractions from blood of control bulls $(\mathrm{n}=5$; solid lines) and dexamethasone-treated test bulls $(\mathrm{n}=60$; dotted lines).

$\ldots, 10$, and $\sigma_{e_{t}}^{2}, t=1,2$, and 3 , respectively. Day-specific heritabilities were estimated as $\hat{h}_{j}^{2}=\frac{\hat{\sigma}_{g_{j}}^{2}}{\hat{\sigma}_{z_{j}}^{2}}, j=1,2,3$, ...,10, whereas BoLA heritabilities were estimated using $\frac{2 \hat{\sigma}_{\text {bola }}^{2}}{\hat{\sigma}_{z_{1}}^{2}}$; i.e., the latter thereby being expressed on a predexamethasone (i.e., d $-5,-4$, and -3 ) basis. Heritability standard errors were determined using the delta method for the variance of a ratio (Mood et al., 1974), given the asymptotic standard errors for the REML variance component estimates as implemented in ASREML.

\section{RESULTS}

\section{Effects of Dexamethasone on Mean Responses}

Day-specific back-transformed means (LSM \pm SEM) for the 8 mononuclear leukocyte traits monitored in this study are presented in Figures 1 to 3 . It is noteworthy that minimal assay variation occurred from study day to study day, as shown by the relatively flat lines 
for control bulls in these figures. On the other hand, lines for test bulls showed significant effects $(P \leq 0.05)$ of dexamethasone on most traits studied. For example, dexamethasone had subtle and variable effects on percentage CD4 T cells (Figure 1a) and percentage CD8 T cells (Figure 1b), these traits being slightly decreased on sample $d 2$ and modestly increased by sample $d 11$ relative to pretreatment values. More strikingly, dexamethasone caused an approximate $72 \%$ reduction in percengate $\mathrm{WC} 1+\gamma \delta \mathrm{T}$ cells, which made up approximately $23 \%$ of all mononuclear leukocytes prior to treatment, reached a nadir of approximately $7 \%$ of all cells on study $\mathrm{d} 2$, and did not return to pretreatment levels even by d 11 (Figure 1c). Dexamethasone also influenced percentage B cells, causing a slight decrease in these cells on $\mathrm{d} 2$ followed by a rebound increase after treatment termination on study d 4 and 5 (Figure 2a). There was no detectable effect of dexamethasone on percentage $\mathrm{MHC} \mathrm{I}^{+}$cells, which showed little variation at all from study day to study day (ranging from roughly 97 to $99 \%$ across days; Figure 2b). However, dexamethasone did cause a reduction in surface expression of MHC I, which was most notable on study d 2 and returned to pretreatment levels by study d 4 (Figure 3a). Unlike percentage $\mathrm{MHC} \mathrm{I}^{+}$cells, the percentage MHC II cells was profoundly affected by dexamethasone administration, increasing from a mean of approximately $28 \%$ before treatment to a plateau of roughly 45 to $50 \%$ across all days post treatment (Figure 2c). Major histocompatibility complex II expression followed a reverse pattern that was similar to that for MHC I expression, dropping to nadir values by study d 2 and recovering to pretreatment levels by study d 5 (Figure $3 b$ ). Thus, dexamethasone induced the same phenotypic changes in circulating mononuclear leukocytes of the current group of 60 test bulls as they did in cattle of previous studies (Burton and Kehrli, 1996; Nonnecke et al., 1997).

\section{Variance Component Estimates}

Inferences on variance components were based on the best fitting common environment variance-covariance structure (i.e., for serial correlation across days within bulls and rounds). As in Tempelman et al. (2002), the homogeneous variance compound symmetry correlation structure for repeated measures within control bulls and the heterogeneous variance power correlation structure for repeated measures within test bulls provided the best fitting models for all traits studied based on Schwarz's Bayesian Criterion (Schwarz, 1978).

The PCR-RFLP-determined BoLA alleles influenced only percentage MHC II cells $(P<0.05)$ and MHC I expression $(P<0.0001)$. In this regard, the BoLA allelic contribution to phenotypic (total) variation was 10.22 $\pm 8.8 \%$ for percentage MHC II cells and $46.5 \pm 14.3 \%$ for MHC I expression. Evidence for significant $(P<0.05)$ genetic variation existed for baseline values of all traits except percentage MHC I+cells $(P \geq 0.1)$ (Table 3$)$. Also, there was evidence of significant $(P<0.02)$ genetic variation in linear recovery following dexamethasone administration for percentage CD4 $\mathrm{T}$ cells, percentage CD8 T cells, and MHC II expression (Table 3). Therefore, these 3 traits possessed additive genetic variation that was influenced by glucocorticoid challenge. Furthermore, genetic correlations between basal values and linear recovery for percentage $\mathrm{CD} 4 \mathrm{~T}$ cells, percentage CD8 T cells, and MHC II expression were significant $(P<0.04)$ and positive, ranging from 0.70 to 0.96 (Table $3)$. Because of the parameterization used for days in modeling linear recovery, these correlations actually indicate that lower trait values at nadir (e.g., $2 \mathrm{~d}$ postdexamethasone) were genetically associated with greater increases in linear recovery.

\section{Heritability Estimates}

Longitudinal heritability estimates for baseline and linear recovery aspects of the mononuclear leukocyte traits studied are presented in Table 4. These results demonstrate that all baseline traits were moderately to highly heritable, with daily predexamethasone estimates ranging from $0.21 \pm 0.03$ to $0.60 \pm 0.06$. Following dexamethasone administration, heritability estimates for percentage $\mathrm{WC} 1+\gamma \delta \mathrm{T}$ cells and percentage $\mathrm{MHC}$ $\mathrm{I}^{+}$cells increased from predexamethasone to postdexamethasone time points to reach highs between study $d$ 2 and 3 (Table 4). In contrast, administration of the glucocorticoid momentarily reduced heritabilities on $d$ 2 for percentage CD4 T cells, percentage CD8 T cells, and MHC II expression compared with values estimated at baseline, before recovering to baseline values again between d 3 and 11 (Table 4). However, these apparent shifts in heritability estimates between pre and postdexamethasone days often showed inverse relationships with residual variances across corresponding sample times, suggesting that these shifts might have been artifacts of high or low residual variances post dexamethasone treatment rather than steroid-related changes in heritability. Regardless, the longitudinal heritability estimates presented in Table 4 showed that virtually all of the mononuclear leukocyte traits measured in this study possessed significant genetic variation before and during recovery from glucocorticoid-induced phenotypic changes.

\section{DISCUSSION}

The objective of this study was to determine whether bovine mononuclear leukocytes exhibit genetic variabil- 
Table 3. Results of ASREML analysis of leukocyte traits measured at baseline and during recovery from dexamethasone treatment. Shown are genetic components estimates $( \pm \mathrm{SE})$, their $P$ values, genetic correlations, and $P$ values for the covariance estimates.

\begin{tabular}{|c|c|c|c|c|c|c|}
\hline \multirow[b]{2}{*}{ Trait } & \multicolumn{2}{|c|}{$\begin{array}{l}\text { Basal genetic } \\
\text { variation }\end{array}$} & \multicolumn{2}{|c|}{$\begin{array}{c}\text { Recovery genetic } \\
\text { variation }\end{array}$} & \multicolumn{2}{|c|}{$\begin{array}{c}\text { Genetic } \\
\text { correlation }\end{array}$} \\
\hline & Estimate (SE) & $P$ & Estimate (SE) & $P$ & Estimate & $P$ \\
\hline Percentage B cells & $\begin{array}{c}0.0023 \\
(0.0012)\end{array}$ & 0.0072 & $\begin{array}{c}0.0026 \\
(0.0012)\end{array}$ & $\mathrm{NS}^{1}$ & 0.001 & NS \\
\hline Percentage CD4 T cells & $\begin{array}{l}0.0016 \\
(0.0004)\end{array}$ & 0.001 & $\begin{array}{l}0.002 \\
(0.0005)\end{array}$ & 0.0153 & 0.70 & 0.0305 \\
\hline Percentage CD8 T cells & $\begin{array}{c}0.0008 \\
(0.0002)\end{array}$ & 0.0001 & $\begin{array}{c}0.0009 \\
(0.0002)\end{array}$ & 0.0075 & 0.73 & 0.019 \\
\hline Percentage $\mathrm{WC}^{2+} \gamma \delta \mathrm{T}$ cells & $\begin{array}{c}0.0017 \\
(0.0004)\end{array}$ & 0.0001 & 0 & $\mathrm{~N} / \mathrm{A}^{3}$ & 0 & N/A \\
\hline Percentage $\mathrm{MHC}^{4} \mathrm{I}$ cells & $\begin{array}{c}0.0011 \\
(0.0006)\end{array}$ & NS & $\begin{array}{c}0.0034 \\
(0.0014)\end{array}$ & NS & 0.64 & NS \\
\hline Percentage MHC II cells & $\begin{array}{c}0.0021 \\
(0.0006)\end{array}$ & 0.0021 & $\begin{array}{c}0.0021 \\
(0.0007)\end{array}$ & NS & 0.10 & NS \\
\hline MHC I expression & $\begin{array}{l}0.0146 \\
(0.0034)\end{array}$ & 0.0001 & $\begin{array}{l}0.014 \\
(0.0035)\end{array}$ & NS & -0.23 & NS \\
\hline MHC II expression & $\begin{array}{c}0.0140 \\
(0.004)\end{array}$ & 0.0004 & $\begin{array}{l}0.0218 \\
(0.0058)\end{array}$ & 0.0007 & 0.96 & 0.0014 \\
\hline
\end{tabular}

\footnotetext{
${ }^{1} \mathrm{NS}=$ Not significant $(P>0.05)$.

${ }^{2} \mathrm{WC} 1=$ Workshop cluster 1 molecule.

${ }^{3} \mathrm{~N} / \mathrm{A}=$ Estimate fixed to near zero.

${ }^{4} \mathrm{MHC}=$ Major histocompatibility complex.
}

ity pre and postchallenge with glucocorticoid hormone in vivo. Test animals included 60 pedigreed Holstein bulls treated on 3 consecutive d with dexamethasone. Eight indicator traits of leukocyte responsiveness to dexamethasone were monitored. As expected from pre- vious studies (Burton and Kehrli, 1996; Nonnecke et al., 1997), dexamethasone administration into test bulls caused pronounced reductions in percentage $\mathrm{WC} 1+\gamma \delta$ T cells and expression of MHC I and MHC II by circulating APC while chronically increasing circulating per-

Table 4. Daily heritability estimates (with standard errors) for 8 mononuclear leukocyte traits monitored before (d -5 ,-4, and -3 ), during (d 2), and after (d 3, 4, 5, 9, 10, and 11) dexamethasone administration (on d 0,1, and 2) into test bulls. All percentage data were arcsin(square root)-transformed, and all expression (mean fluorescence intensity, MFI) data were log-transformed prior to statistical analyses.

\begin{tabular}{|c|c|c|c|c|c|c|c|c|}
\hline & $\begin{array}{l}\text { Percentage } \\
\text { B cells }\end{array}$ & $\begin{array}{l}\text { Percentage } \\
\text { CD4 T cells }\end{array}$ & $\begin{array}{l}\text { Percentage } \\
\text { CD8 T cells }\end{array}$ & $\begin{array}{l}\text { Percentage } \\
\text { WC1 } 1^{1}+\gamma \delta \\
\text { T cells }\end{array}$ & $\begin{array}{l}\text { Percentage } \\
\text { MHC }^{2} \text { I cells }\end{array}$ & $\begin{array}{l}\text { Percentage } \\
\text { MHC II cells }\end{array}$ & $\begin{array}{l}\text { MHC I } \\
\text { expression }\end{array}$ & $\begin{array}{l}\text { MHC II } \\
\text { expression }\end{array}$ \\
\hline$d-5$ & $\begin{array}{c}0.21 \\
(0.03)\end{array}$ & $\begin{array}{c}0.49 \\
(0.07)\end{array}$ & $\begin{array}{c}0.60 \\
(0.06)\end{array}$ & $\begin{array}{c}0.29 \\
(0.04)\end{array}$ & $\begin{array}{c}0.21 \\
(0.08)\end{array}$ & $\begin{array}{c}0.33 \\
(0.10)\end{array}$ & $\begin{array}{c}0.31 \\
(0.10)\end{array}$ & $\begin{array}{c}0.40 \\
(0.08)\end{array}$ \\
\hline $\mathrm{d}-4$ & $\begin{array}{c}0.21 \\
(0.03)\end{array}$ & $\begin{array}{c}0.49 \\
(0.07)\end{array}$ & $\begin{array}{c}0.60 \\
(0.06)\end{array}$ & $\begin{array}{c}0.29 \\
(0.04)\end{array}$ & $\begin{array}{c}0.21 \\
(0.08)\end{array}$ & $\begin{array}{c}0.33 \\
(0.10)\end{array}$ & $\begin{array}{c}0.31 \\
(0.10)\end{array}$ & $\begin{array}{c}0.40 \\
(0.08)\end{array}$ \\
\hline$d-3$ & $\begin{array}{c}0.21 \\
(0.03)\end{array}$ & $\begin{array}{c}0.49 \\
(0.07)\end{array}$ & $\begin{array}{c}0.60 \\
(0.06)\end{array}$ & $\begin{array}{l}0.29 \\
(0.04)\end{array}$ & $\begin{array}{c}0.21 \\
(0.08)\end{array}$ & $\begin{array}{c}0.33 \\
(0.10)\end{array}$ & $\begin{array}{c}0.31 \\
(0.10)\end{array}$ & $\begin{array}{c}0.40 \\
(0.08)\end{array}$ \\
\hline d 3 & $\begin{array}{l}0.20 \\
(0.03)\end{array}$ & $\begin{array}{c}0.45 \\
(0.10)\end{array}$ & $\begin{array}{l}0.50 \\
(0.11)\end{array}$ & $\begin{array}{c}0.68 \\
(0.10)\end{array}$ & $\begin{array}{l}0.98 \\
(0.06)\end{array}$ & $\begin{array}{c}0.35 \\
(0.16)\end{array}$ & $\begin{array}{c}0.30 \\
(0.10)\end{array}$ & $\begin{array}{c}0.27 \\
(0.09)\end{array}$ \\
\hline d 4 & $\begin{array}{l}0.15 \\
(0.03)\end{array}$ & $\begin{array}{c}0.44 \\
(0.09)\end{array}$ & $\begin{array}{c}0.08 \\
(0.02)\end{array}$ & $\begin{array}{c}0.50 \\
(0.08)\end{array}$ & $\begin{array}{c}0.46 \\
(0.10)\end{array}$ & $\begin{array}{c}0.33 \\
(0.13)\end{array}$ & $\begin{array}{c}0.31 \\
(0.10)\end{array}$ & $\begin{array}{c}0.40 \\
(0.12)\end{array}$ \\
\hline d 5 & $\begin{array}{l}0.20 \\
(0.04)\end{array}$ & $\begin{array}{c}0.42 \\
(0.08)\end{array}$ & $\begin{array}{l}0.29 \\
(0.07)\end{array}$ & $\begin{array}{c}0.41 \\
(0.07)\end{array}$ & $\begin{array}{c}0.37 \\
(0.10)\end{array}$ & $\begin{array}{c}0.26 \\
(0.09)\end{array}$ & $\begin{array}{c}0.31 \\
(0.10)\end{array}$ & $\begin{array}{c}0.39 \\
(0.10)\end{array}$ \\
\hline
\end{tabular}

${ }^{1} \mathrm{WC} 1=$ Workshop cluster 1 molecule.

${ }^{2} \mathrm{MHC}=$ Major histocompatibility complex. 


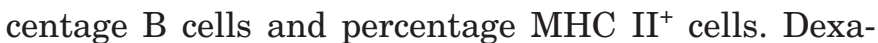
methasone effects on percentage CD4 and percentage CD8 T cells were subtle and pleiotropic but clearly observable. In contrast, daily values for all traits remained stable for control bulls, which were not treated with dexamethasone and whose cells were used simply as assay controls.

A novel finding of this study was that the traits studied all exhibited at least some degree of genetic variation (Tables 3 and 4). This fact may be important for the following reasons. Mononuclear leukocytes serve as important APC by using their MHC I and II molecules to present peptide antigens to antigen-specific CD8 cytotoxic $\mathrm{T}$ cells and CD4 helper $\mathrm{T}$ cells during induction phases of cell mediated, inflammatory, and humoral immune responses against pathogenic microorganisms. In light of this, it was noteworthy that BoLA DRB3.2 (i.e., MHC II) alleles contributed significantly to total variation in percentage $\mathrm{MHC} \mathrm{II}^{+}$cells and $\mathrm{MHC}$ I expression. It was curious that BoLA alleles did not influence variation in MHC II expression itself. However, as suggested by the plots in Figures $2 \mathrm{c}$ and $3 \mathrm{~b}$, it is possible that variations in level of MHC II expression per APC are counteracted by corresponding changes in circulating numbers of MHC II-bearing cells, which was influenced by BoLA. If true, these findings suggest 2 things: 1 ) that animals might have a genetic predisposition to recover the critical MHC I and II antigen-presenting systems following stress-induced increases in blood glucocorticoid concentrations and 2) that additional genetic variation may be determined by polymorphism at the MHC II locus (BoLA DRB3.2). It was thus encouraging that genetic variation for recovery of $\mathrm{MHC}$ II expression, percentage CD4 $\mathrm{T}$ cells, and percentage CD8 $\mathrm{T}$ cells was significant, and that the traits genetically correlated with each other (Table 3 ), because this suggests that recovery of adaptive immunocompetence following stress (i.e., glucocorticoid challenge) may be exploited by genetic selection.

A second novel finding of this study was that baseline (i.e., predexamethasone) levels of all traits exhibited significant genetic variation with moderate to high daily heritability estimates (Tables 3 and 4). All traits studied are potentially important indicators of the basal immunocompetence status of animals (Burton and Erskine, 2003). Therefore, the current study indicates that it may be possible to genetically select dairy bulls for improved basal levels of circulating mononuclear leukocyte subsets and MHC I and II expression on APC, provided that new knowledge is gained on what constitutes a "superior" vs. "inferior" immunocompetence profile. In future studies, it would seem particularly relevant to examine such variation in the context of disease challenges with agriculturally relevant pathogens, ei- ther in the test bulls themselves or in their daughters. Peripartum mastitis would seem to be a good model for disease testing in daughters of the bulls, because parturition is associated with high blood glucocorticoid concentrations and mastitis susceptibility (Burton and Erskine, 2003) and because heritable phenotypic changes occur in blood leukocytes at parturition (Detilleux et al., 1994) that are similar to those observed in the current study. Finally, given the potential for genetic improvement in baseline and recovery aspects of immunocompetence in glucocorticoid-challenged bulls inferred from this study, a much larger group of AI sires should also be studied in the future. Such a study would both substantiate our results and help determine whether a bull's genetic merit for baseline and/or recovery of immunocompetence following glucocorticoid challenge is predictive of his daughters' health status and milk somatic cell score tests in the field.

\section{CONCLUSIONS}

Results of this study support a hypothesis that baseline phenotypes of circulating mononuclear leukocytes are influenced by genetic variation and that MHC II alleles contribute additional genetic variation to levels of circulating MHC II-bearing cells and to MHC I expression on blood leukocytes. Thus, it is reasonable to expect that the mononuclear leukocyte traits studied can be improved by genetic selection. However, it remains to be shown which of the traits studied in this work may be appropriate candidates for genetic selection, including which direction of genetic change would improve general immunocompetence and resistance to specific pathogens in animals stressed by the environment or parturition.

\section{ACKNOWLEDGMENTS}

This research was supported by 21st Century Genetics CRI, USDA CRIS Project \#3625-32000-003-00D (M. E. Kehrli), the Michigan Agricultural Experiment Station [Project numbers MICL 01822 and 01836 (J. L. Burton and R. J. Templeman)], the Iowa Agricultural Experiment Station (A. E. Freeman), and a Postdoctoral Fellowship grant from the Natural Sciences and Engineering Research Council of Canada (J. L. Burton). Sincere thanks are extended to Arlon Anderson, Sally Crandell, and Wendy Johnson for technical assistance during blood processing and enrichment of mononuclear leukocytes.

\section{REFERENCES}

Anderson, B. H., D. L. Watson, and I. G. Colditz. 1999. The effect of dexamethasone on some immunological parameters in cattle. Vet. Res. Commun. 23:399-413. 
Burton, J. L., and R. J. Erskine. 2003. Immunity and mastitis: Some new ideas for an old disease. Vet. Clin. North Am. Food Anim. Pract. 19:1-45.

Burton, J. L., and M. E. Kehrli, Jr. 1995. Regulation of neutrophil adhesion molecules, and shedding of Staphylococcus aureus in milk of cortisol- and dexamethasone-treated cows. Am. J. Vet. Res. 56:997-1006.

Burton, J. L., and M. E. Kehrli, Jr. 1996. Effects of dexamethasone on bovine circulating $\mathrm{T}$ lymphocyte populations. J. Leuk. Biol. 59:90-99.

Burton, J. L., M. E. Kehrli, Jr., S. Kapil, and R. L. Horst. 1995. Regulation of L-selectin and CD18 on bovine neutrophils by glucocorticoids: effects of cortisol and dexamethasone. J Leuk Biol. 57:317-325.

Chiang, Y. W., J. A. Roth, and J. J. Andrews. 1990. Influence of recombinant bovine interferon gamma and dexamethasone on pneumonia attributable to Haemophilus somnus in calves. Am. J. Vet. Res. 51:759-762.

Cronstein, B. N., S. C. Kimmel, R. I. Levin, F. Martiniuk, and G. Weissmann. 1992. A mechanism for the antiinflammatory effects of corticosteroids: the glucocorticoid receptor regulates leukocyte adhesion to endothelial cells and expression of endothelial-leukocyte adhesion molecule 1 and intercellular adhesion molecule 1. Proc. Natl. Acad. Sci. USA 89:9991-9995.

Detilleux, J. C., K. J. Koehler, A. E. Freeman, M. E. Kehrli, Jr., and D. H. Kelley. 1994. Immunological parameters of periparturient Holstein cattle: Genetic variation. J. Dairy Sci. 77:2640-2650.

Dietz, A. B., J. C. Detilleux, A. E. Freeman, D. H. Kelley, J. R. Stabel, and M. E. Kehrli, Jr. 1997. Genetic association of bovine lymphocyte antigen DRB3 allelles with immunological traits of Holstein cattle. J. Dairy Sci. 80:400-405.

Eicher, S., and J. L. Burton. 2004. Immune System: Stress Effects. Encyclopedia of Animal Science. W. C. Pond and A. W. Bell, ed. Marcel Dekker Inc., New York.

Gilmour, A. R., B. R. Cullis, S. J. Welham, and R. Thompson. 2001. ASRENL manual. NSW Agriculture, Orange, 2800, Australia (accessed from anonymous ftp: ftp.res.bbsrc.ac.uk in pub/aar).

Gilmour, A. R., R. Thompson, and B. R. Cullis. 1995. Average information REML, an efficient algorithm for variance parameter estimation in linear mixed models. Biometrics 51:1440-1450.

Henderson, C. R. 1976. Inverse of a matrix of relationships due to sires and maternal grandsires in an inbred population. J. Dairy Sci. 59:1585-1588.

Kehrli, M. E., Jr., and J. A. Harp. 2001. Immunity in the mammary gland. Vet. Clin. North Am. Food Anim. Pract. 17:495-516.

Kehrli, M. E., Jr., B. J. Nonnecke, and J. A. Roth. 1989. Alterations in bovine peripheral blood lymphocyte function during the peripartum period. Am. J. Vet. Res. 50:215-220.

Kelm, S. C., J. C. Detilleux, A. E. Freeman, M. E. Kehrli, Jr., A. B. Dietz, L. K. Fox, J. E. Butler, I. Kasckovics, and D. H. Kelley. 1997. Genetic association between parameters of inmate immunity and measures of mastitis in periparturient Holstein cattle. J. Dairy Sci. 80:1767-1775.

Lohuis, J. A. C. M., W. Van Leeuwen, J. H. M. Verheijden, A. S. J. P. A. M. Van Miert, and A. Brand. 1988. Effect of dexamethasone on experimental Escherichia coli mastitis in the cow. J. Dairy Sci. 71:2782-2789.

Madsen, S. A., L.-C. Chang, M.-C. Hickey, G. J. M. Rosa, P. M. Coussens, and J. L. Burton. 2004. Microarray analysis of gene expression in blood neutrophils of parturient cows. Physiol. Genomics 16:212-221.

Mood, A. M., F. A. Graybill, and D. C. Boes. 1974. Introduction to the Theory of Statistics. 3rd edition. McGraw and Hill, New York.

Nonnecke, B. J., J. L. Burton, and M. E. Kehrli, Jr. 1997. Associations between function and composition of blood mononuclear leukocyte populations from Holstein bulls treated with dexamethasone. J. Dairy Sci. 80:2403-2410.

Oldham, G., and C. J. Howard. 1992. Suppression of bovine lymphocyte responses to mitogens following in vivo and in vitro treatment with dexamethasone. Vet. Immunol. Immunopathol. 30:161-177.

Preisler, M. T., P. S. D. Weber, R. J. Tempelman, R. J. Erskine, H. Hunt, and J. L. Burton. 2000. Glucocorticoid receptor expression profiles in mononuclear leukocytes of periparturient Holstein cows. J. Dairy Sci. 83:38-47.

Roth, J. A., and M. L. Kaeberle. 1982. Effect of glucocorticoids on the bovine immune system. J. Am. Vet. Med. Assoc. 180:894-901.

Roth, J. A., M. L. Kaeberle, and R. D. Hubbard. 1984. Attempts to use thiabendazole to improve the immune response in dexamethasone-treated or stressed cattle. Immunopharmacol. 8:121-128.

Schwarz, G. 1978. Estimating the dimension of a model. Ann. Stat. 6:461-464.

Searle, S. R. 1982. Matrix Algebra Useful for Statistics. Wiley, New York, NY.

Stram, D. O., and J. W. Lee. 1994. Variance component testing in the longitudinal mixed effects model. Biometrics 50:1171-1177.

Tempelman, R. J., P. M. Saama, A. E. Freeman, S. C. Kelm, A. L. Kuck, M. E. Kehrli, Jr., and J. L. Burton. 2002. Genetic variation in bovine neutrophil sensitivity to glucocorticoid challenge. Acta Agric. Scand. 52:189-202.

Van Arendonk, J. A. M., M. C. A. M. Bink, P. Bijma, H. Bovenhuis, D. J. DeKoning, and E. W. Brascamp. 1999. Use of phenotype and molecular data for genetic evaluation of livestock. Pages 60 69 in From Jay Lush to Genomics, Visions for Animal Breeding and Genetics. J. C. M Dekkers, S. J. Lamont, and M. F. Rothschild, ed. Iowa State University, Ames, IA.

Weber, P. S. D., S. A. Madsen, G. W. Smith, J. J. Ireland, and J. L. Burton. 2001. Pre-translational regulation of neutrophil CD62L in glucocorticoid-challenged cattle. Vet. Immunol. Immunopathol. 83:213-240.

Weber, P. S. D., T. Toelboell, L.-C. Chang, J. Durrett Tirrell, P. M. Saama, G. W. Smith, and J. L. Burton. 2004. Mechanisms of glucocorticoid-induced down regulation of neutrophil L-selectin: Evidence for effects at the gene expression level and primarily on blood neutrophils. J. Leuk. Biol. 75:815-827.

Wesley, I. V., J. H. Bryner, M. J. Van der Maaten, and M. Kehrli. 1989. Effects of dexamethasone on shedding of Listeria monocytogenes in dairy cattle. Am. J. Vet. Res. 50:2009-2013.

Yu, P. W., L. A. Schuler, M. Kehrli, L. Mattocks, B. J. Nonnecke, and C. J. Czuprynski. 1997. Effects of dexamethasone treatment on IL-1 receptor mRNA levels in vivo. J. Leuk. Biol. 62:401-404. 